\title{
High prevalence of hyperuricemia and lack of association with rs2280205 and rs6820230 alleles of the SLC2A9 gene in urban Bangkok, Thailand
}

\author{
S. Wannaiampikul ${ }^{1}$, P. Sangsawangchot ${ }^{2}$ and C. Tanunyutthawongse ${ }^{1}$ \\ ${ }^{1}$ Department of Biochemistry, Faculty of Medicine, Srinakharinwirot \\ University, Thailand \\ ${ }^{2}$ Rheumatology unit, Faculty of Medicine, Srinakharinwirot University, \\ HRH Princess Maha Chakri Sirindhorn Medical Center, Thailand
}

Corresponding author: C. Tanunyutthawongse

E-mail: morchantra@gmail.com

Genet. Mol. Res. 19 (1): gmr18511

Received October 28, 2019

Accepted March 03, 2020

Published March 30, 2020

DOI http://dx.doi.org/10.4238/gmr18511

\begin{abstract}
Genetic variants of SLC2A9 have been reported to be associated with deficiencies in the excretion of urate and with urate transporter gene 9 (GLUT9) activity. However, the evidence remains inconclusive and no information is available about SLC2A9 genetic variants (rs2280205 and rs6820230) association with hyperuricemia (HUA) in the Thai population. We decided to determine whether rs2280205 and rs6820230 alleles of the SLC2A9 gene are associated with HUA in a cross-sectional study that included 193 subjects in urban Bangkok, Thailand. These single-nucleotide polymorphisms were analyzed using unconditional logistic regression. The prevalence of HUA was $31.1 \%$. Males (HUA defined as serum urate levels $>7.0 \mathrm{mg} / \mathrm{dL}$ ) had a higher prevalence of HUA than females $(>6.0 \mathrm{mg} / \mathrm{dL})(42.7$ versus $24.8 \%)$. By SLC2A9 SNP association analysis, the rs 2280205 and rs6820230 variants were not significantly associated with HUA (adjusted odds ratio $(\mathrm{aOR})=5.59,95 \% \mathrm{CI}=$ $0.50-62.95 ; \mathrm{aOR}=0.77,95 \% \mathrm{CI}=0.11-5.45)$, respectively). The prevalence of HUA was much higher in this urban Thai population than in similar studies in rural areas of the country and also compared to the mean frequency in developed countries such as the USA (usually $10 \%$ or less). The haplotypes rs6820230 and rs2280205 did
\end{abstract}


not influence the risk for HUA in these Bangkok subjects. We concluded that the prevalence of HUA is extremely high in urban Bangkok and that these SNPs are not associated with HUA in this population.

Key words: SLC2A9 gene; rs2280205 variants; rs6820230 variants; hyperuricemia; urban population; prevalence

\section{INTRODUCTION}

Abnormalities in uric acid metabolism are one of the major causes of both hyperuricemia (HUA) and gout development (Terkeltaub, 2003). The several previous epidemiologic studies indicated that the prevalence of HUA is rapidly increasing in the world population. The previous evidences showed that HUA is not prevalent only in the developed countries (Zhu et al., 2011; Liu et al., 2015; Bardin et al., 2016), but also increasing in the developing countries including rural and urban population in Thailand (Lohsoonthorn et al., 2006; Premgamone et al., 2011), and urban population in Turkey (Sari et al., 2009). HUA is caused by environmental factors such as obesity, purine abundant diet and alcohol intake (Nakanishi et al., 2001; Premgamone et al., 2011; Ali N et al., 2018). Thus, HUA is considered to be a common lifestyle disorder in humans. However, the environmental factors (less than 1\%) explained much less variance in serum uric acid levels when compared with inherited genetic variants (approximately 24\%) (Major et al., 2018). For instance, the SLC2A9 gene variants at different loci such as rs3733591, rs12498742, rs12509955, a gene linked to the transport of uric acid in the kidneys and also changing the activity of urate transporter genes 9 (GLUT9) (Hurba et al., 2014), seem to have the most strongly influence on urate levels and gout (Dehghan et al., 2008; Kottgen et al., 2013; Dalbeth et al., 2016; Zhang et al., 2016). A recent study has found the rs2280205 reduces susceptibility to gout (32\%); while, rs6820230 was associated with susceptibility to gout in Caucasian approximately 2-fold (Chisnall, 2014). In contrast, some previous studies in various ethnic populations such as the Czech population, Cameroonians, and Amish have demonstrated that these genetic variants are not associated with HUA and gout (McArdle et al., 2008; Hurba et al., 2014; Nkeck et al., 2018). Although these genetic variants could affect the expression of the SLC2A9 gene, which can enhance the risk of HUA development, the roles of some associated genes are unclear and no information is available on the association of these genetic variants with HUA development among Thais living in urban areas. Therefore, we examined the prevalence of HUA and possible associations of rs2280205 and rs6820230 variants of the SLC2A9 gene with the risk of HUA to help estimate the genetic risk factor for HUA in urban Thailand.

\section{MATERIAL AND METHODS}

\section{Study population}

An urban community based cross-sectional analytical study was conducted from June 2017 to June 2018. The subjects aged 18 years and over were 193 health checkup examinees in the SWU-clinic, Faculty of Medicine, Srinakharinwirot University (SWU). 
The HUA group is defined as his/her baseline serum uric acid level (SUA) higher than 7.0 $\mathrm{mg} / \mathrm{dL}$ in males and $6.0 \mathrm{mg} / \mathrm{dL}$ in females, do not appear as specific for the diagnosis of gout, and there was no clinically overt gout. The 193 subjects had no arthritis. All participants with cardiovascular disease due to acute heart disease, kidney disease or kidney dysfunction, cancer, other stress or used anti-depression drugs and also using drugs that lower SUA concentrations were excluded from the study. Written informed consent including genotyping permission was obtained from all participants. The ethics committee of Srinakharinwirot University, Thailand approved the study protocol (MEDSWUEC148/60E).

\section{Clinical and biochemical collection}

For each participant, systolic blood pressure (SBP) and diastolic blood pressure (DBP) was measured using an automatic sphygmomanometer. Obesity is identified from body mass index (BMI) according to Asian population criteria (WHO, 2004). The health checkup data was used for this study including total cholesterol (TC), triglyceride (TG), and high-and-low density lipoprotein cholesterol (HDL-C and LDL-C, respectively), fasting plasma glucose (FPG), and SUA level using an automatic biochemical analyzer (Abbott CI 8200, USA).

\section{Identification of genotyping}

The two common rs2280205 (G/A) and rs6820230 (C/T) variants of SLC2A9 gene were analyzed in each participant. DNA was extracted from peripheral blood leucocyte samples obtained from each participant using a DNA extraction kit (QIAamp DNA Mini $\mathrm{Kit}^{\circledR}$, Qiagen) and stored at $-80^{\circ} \mathrm{C}$ until using for the clinical chemistry assays. Two common variants were detected using TaqMan SNP Genotyping Assays by StepOnePlus ${ }^{\circledR}$ Real-Time PCR Systems (Applied Biosystems, USA).

\section{Statistical analysis}

Statistical analyses were performed using the STATA version 14 (StataCorp, College Station, TX). To examine the associations of the two polymorphisms, the haplotypes were assessed using unconditional logistic regression models adjusted by all covariates. The chi-square test was used to estimate Hardy-Weinberg equilibrium (HWE). Linkage disequilibrium (LD) and haplotype frequencies were performed using the SNPStats web tool (Sole et al., 2006). P-value less than 5\% were estimated to indicate statistically significant.

\section{RESULTS}

The baseline characteristics of the present study are summarized in Table 1. A total of 193 participants were 68 males and 125 females. The mean age of participants was 47.43 \pm 15.35 years. Most participants were married and had hypertension with dyslipidemia. Male subjects had a higher weight, BMI, SBP, DBP, TG, and with lower HDL-C compared to female subjects. However, TC and LDL-C levels were high in both male and female 
subjects (Table 1). Based on the diagnostic criteria, the prevalence of HUA from this study in the urban area was $31.1 \%$. Moreover, the estimated prevalence of HUA in males was higher than in female subjects. Separating by age group, most HUA were age 31-45 years, while the prevalence of HUA among the older (over 60 years) was $31.9 \%$ as shown in Table 2.

Table 1. Baseline characteristics among urban population according to gender.

\begin{tabular}{|c|c|c|c|}
\hline Characteristics & Total & Males & Females \\
\hline Number of participants & 193 & 68 & 125 \\
\hline Age (years) & $47.43 \pm 15.35$ & $50.41 \pm 14.58$ & $45.79 \pm 15.58$ \\
\hline \multicolumn{4}{|l|}{ Status, $\mathrm{n}$} \\
\hline Single & 78 & 25 & 53 \\
\hline Married & 115 & 35 & 80 \\
\hline \multicolumn{4}{|l|}{ Underlying disease, $\mathrm{n}$} \\
\hline Dyslipidemia (DLP) & 7 & 2 & 5 \\
\hline Diabetes mellitus (DM) & 2 & 1 & 1 \\
\hline Hypertension (HTN) & 6 & 2 & 4 \\
\hline HTN/ DLP & 16 & 6 & 10 \\
\hline DM/DLP & 5 & 3 & 2 \\
\hline HTN/ DM / DLP & 5 & 1 & 4 \\
\hline HTN/DLP/ BPH & 1 & 1 & 0 \\
\hline Hypothyroidism & 2 & 0 & 2 \\
\hline Weight $(\mathrm{kg})$ & $65.78 \pm 14.48$ & $75.06 \pm 14.12$ & $60.73 \pm 11.99$ \\
\hline Body mass index $\left(\mathrm{kg} / \mathrm{m}^{2}\right)$ & $24.91 \pm 4.78$ & $26.24 \pm 4.27$ & $24.19 \pm 4.90$ \\
\hline Systolic blood pressure $(\mathrm{mmHg})$ & $126.55 \pm 15.80$ & $131.56 \pm 11.73$ & $123.83 \pm 17.06$ \\
\hline Diastolic blood pressure $(\mathrm{mmHg})$ & $77.19 \pm 10.56$ & $81.30 \pm 9.76$ & $74.95 \pm 10.33$ \\
\hline Total cholesterol $(\mathrm{mg} / \mathrm{dL})$ & $208.78 \pm 35.60$ & $209.25 \pm 41.63$ & $208.53 \pm 32.09$ \\
\hline Triglycerides (mg/dL) & $127.84 \pm 64.68$ & $155.00 \pm 84.78$ & $113.27 \pm 44.78$ \\
\hline High density lipoprotein cholesterol & $59.14 \pm 14.10$ & $54.82 \pm 16.08$ & $61.47 \pm 12.38$ \\
\hline Low density lipoprotein cholesterol & $128.51 \pm 33.75$ & $126.89 \pm 38.97$ & $129.37 \pm 30.72$ \\
\hline Fasting plasma glucose (mg/dL) & $99.11 \pm 28.84$ & $106.96 \pm 42.48$ & $94.85 \pm 16.13$ \\
\hline Serum uric acid (mg/dL) & $5.90 \pm 1.30$ & $6.85 \pm 1.27$ & $5.38 \pm 1.00$ \\
\hline
\end{tabular}

$\mathrm{BPH}$ : benign prostatic hyperplasia; Data is presented as mean \pm standard deviation (SD)

Table 2. Calculation of prevalence of hyperuricemia according to sex and age group among the urban Bangkok population.

\begin{tabular}{|c|c|c|c|}
\hline Groups & No. of population & No. of HUA & Prevalence $(\%)$ \\
\hline Overall & 193 & 60 & 31.1 \\
\hline \multicolumn{4}{|l|}{ Gender } \\
\hline Male & 68 & 29 & 42.7 \\
\hline Female & 125 & 31 & 24.8 \\
\hline \multicolumn{4}{|l|}{ Age group } \\
\hline$<30$ & 30 & 5 & 16.7 \\
\hline $31-45$ & 64 & 23 & 35.9 \\
\hline $46-59$ & 52 & 17 & 32.7 \\
\hline $60+$ & 47 & 15 & 31.9 \\
\hline
\end{tabular}

No. $=$ Number

In this study, the three participants without a genotyping were excluded from the analysis; therefore 190 subjects remained. The two common rs2280205 and rs6820230 of SLC2A9 gene were tested in Hardy-Weinberg equilibrium (HWE). The 
frequency of G/G genotypes of rs2280205 variant was high in both HUA and control subjects (60\% and 62\%, respectively), including C/C genotypes of rs6820230 variant also high in both subjects (Table 3). We analyzed the association of two variants using genetic models with unconditional logistic regression. Our results found that the two variants were not associated with a risk for development of HUA with any models (Table 4).

Table 3. Genotype distribution of rs 2280205 and rs6820230 alleles of the SLC2A9 gene according to hyperuricemia (HUA) condition in an urban Bangkok population.

\begin{tabular}{|c|c|c|c|c|c|c|c|c|}
\hline \multirow{2}{*}{ SNPs } & \multirow{2}{*}{ Group } & \multirow{2}{*}{$\mathbf{n}$} & \multicolumn{3}{|c|}{ Genotype, n (\%) } & \multicolumn{2}{|c|}{ Allele, n (\%) } & \multirow{2}{*}{$\begin{array}{l}\text { HWE } \\
\text { P-value }\end{array}$} \\
\hline & & & G/G & G/A & $\mathbf{A} / \mathbf{A}$ & $\mathbf{G}$ & $\mathbf{A}$ & \\
\hline \multirow[t]{2}{*}{ rs2280205 } & HUA & 60 & $36(60)$ & $19(32)$ & $5(8)$ & $91(76)$ & $29(24)$ & \multirow[t]{2}{*}{0.530} \\
\hline & Control & 130 & $81(62)$ & $43(33)$ & $6(6)$ & $205(79)$ & $55(21)$ & \\
\hline \multirow{2}{*}{ SNPs } & \multirow{2}{*}{ Group } & \multirow{2}{*}{$\mathrm{n}$} & \multicolumn{3}{|c|}{ Genotype, n (\%) } & \multicolumn{2}{|c|}{ Allele, n (\%) } & HWE \\
\hline & & & $\mathrm{C} / \mathrm{C}$ & $\mathrm{C} / \mathrm{T}$ & $\mathrm{T} / \mathrm{T}$ & $\mathrm{C}$ & $\mathrm{T}$ & $\mathrm{P}$-value \\
\hline \multirow[t]{2}{*}{ rs6820230 } & HUA & 60 & $51(85)$ & $9(15)$ & 0 & $111(92)$ & $9(8)$ & 0.610 \\
\hline & Control & 130 & $110(85)$ & $20(15)$ & 0 & $240(92)$ & $20(8)$ & \\
\hline
\end{tabular}

WE: Hardy-Weinberg equilibrium; n: number of individual

Table 4. Odds ratio for association of rs2280205 and rs6820230 with hyperuricemia risk in each model.

\begin{tabular}{|c|c|c|c|c|}
\hline SNPs & Model & Genotype & $\begin{array}{l}\text { OR } \\
(95 \% \text { CI }), \text { P-value }\end{array}$ & $\begin{array}{l}\mathrm{aOR}^{*} \\
(95 \% \mathrm{CI}), \text { P-value }\end{array}$ \\
\hline \multirow[t]{8}{*}{ rs2280205 } & Codominant & $\mathrm{G} / \mathrm{G}$ & 1.00 & 1.00 \\
\hline & - & $\mathrm{G} / \mathrm{A}$ & $0.99(0.51-1.94), 0.986$ & $1.19(0.56-2.53), 0.639$ \\
\hline & - & $\mathrm{A} / \mathrm{A}$ & $1.87(0.54-6.54), 0.324$ & $1.87(0.47-7.36), 0.373$ \\
\hline & Dominant & $\mathrm{G} / \mathrm{G}$ & 1.00 & 1.00 \\
\hline & - & $\mathrm{G} / \mathrm{A}-\mathrm{A} / \mathrm{A}$ & $1.10(0.59-2.06), 0.761$ & $1.29(0.64-2.62), 0.474$ \\
\hline & Recessive & G/G-G/A & 1.00 & 1.00 \\
\hline & - & $\mathrm{A} / \mathrm{A}$ & $1.88(0.55-6.42), 0.314$ & $1.75(0.46-6.74), 0.414$ \\
\hline & Log-additive & - & $1.18(0.71-1.94), 0.520$ & $1.28(0.74-2.23), 0.380$ \\
\hline \multirow[t]{2}{*}{ rs6820230 } & Dominant & $\mathrm{C} / \mathrm{C}$ & 1.00 & 1.00 \\
\hline & - & $\mathrm{C} / \mathrm{T}-\mathrm{T} / \mathrm{T}$ & $0.97(0.41-2.28), 0.945$ & $0.98(0.39-2.51), 0.973$ \\
\hline
\end{tabular}

HUA: hyperuricemia; OR: unadjusted covariate odds ratio; *adjusted odds ratio (aOR) for age, sex, obesity (cut-off point as body mass index $\geq 25 \mathrm{~kg} / \mathrm{m}^{2}$ ), diabetes with pre-diabetes (Fasting glucose $\geq 100 \mathrm{mg} / \mathrm{dL}$ ), hypertriglyceridemia: $\mathrm{TG} \geq 150 \mathrm{mg} / \mathrm{dL}$ or on medication for elevated TG, low HDL-C; HDL-C $<40 \mathrm{mg} / \mathrm{dL}$ in men and $<50 \mathrm{mg} / \mathrm{dL}$ in women or on medications, and hypertension with pre-hypertension (Systolic blood pressure >130 or Diastolic blood pressure $>85 \mathrm{mmHg}$ ); all odds ratio was used unconditional logistics regression.

The pairwise linkage disequilibrium (LD) analysis between two variants was measured, and we found that the results of D' values between rs2280205 and rs6820230 was more than 0.750 . Therefore, the haplotype analysis between the two variants was performed by using the SNPStats web tool (available online at https://www.snpstats.net). The rs6820230 and rs2280205 haplotype C/A and T/G were not associated with HUA (Table 5). 
Table 5. Distribution of haplotype frequencies and their association with hyperuricemia (HUA) in an urban Bangkok population.

\begin{tabular}{|c|c|c|c|c|c|c|c|}
\hline \multicolumn{3}{|c|}{ Haplotype } & \multicolumn{3}{|c|}{ Haplotype freq. } & \multirow{2}{*}{$\begin{array}{c}\text { OR } \\
(95 \% \text { CI }), \\
\text { P-value }\end{array}$} & \multirow{2}{*}{$\begin{array}{c}\text { aOR* } \\
\text { (95\% CI), } \\
\text { P-value }\end{array}$} \\
\hline rs682 & & rs2280205 & Total & $\begin{array}{l}\text { HUA } \\
(n=60)\end{array}$ & $\begin{array}{l}\text { Control } \\
(n=130)\end{array}$ & & \\
\hline \multirow[t]{4}{*}{ Ref. } & $\mathrm{C}$ & $\mathrm{G}$ & 0.710 & 0.706 & 0.712 & 1.00 & 1.00 \\
\hline & $\mathrm{C}$ & A & 0.214 & 0.219 & 0.212 & $\begin{array}{l}1.02(0.59-1.74) \\
0.950\end{array}$ & $\begin{array}{l}1.17(0.65-2.10) \text {, } \\
0.610\end{array}$ \\
\hline & $\mathrm{T}$ & $\mathrm{G}$ & 0.069 & 0.052 & 0.078 & $\begin{array}{l}0.67(0.24-1.90) \\
0.460\end{array}$ & $\begin{array}{l}0.80(0.27-2.33) \\
0.680\end{array}$ \\
\hline & $\mathrm{T}$ & A & 0.008 & 0.023 & 0 & - & - \\
\hline
\end{tabular}

Ref.: Reference group; Haplotype freq: haplotype frequencies; HUA: hyperuricemia; OR: Odds ratio were unadjusted covariates. *Adjusted Odds ratio (aOR) was adjusted for age, gender, obesity, diabetes with pre-diabetes (Fasting glucose $\geq 100 \mathrm{mg} / \mathrm{dL}$ ), hypertriglyceridemia: TG $\geq 150 \mathrm{mg} / \mathrm{dL}$ or on medication for elevated TG, low HDL-C; HDL-C < $40 \mathrm{mg} / \mathrm{dL}$ in men and $<50 \mathrm{mg} / \mathrm{dL}$ in women or on medications, and hypertension with pre-hypertension (Systolic blood pressure $>130$ or Diastolic blood pressure $>85 \mathrm{mmHg}$ ).

\section{DISCUSSION}

In this urban community based cross-sectional analytical study, we systematically analyzed the prevalence of HUA in urban population, Bangkok, Thailand. To our knowledge, this is the first study to focus on the urban community and to investigate the genetic factor to HUA. In our results, the prevalence of HUA in the urban population was higher than that observed in several developed countries, such as mainland China (Liu et al., 2015) and Japan (Nagahama et al., 2004). As expected, the prevalence is higher than in developing countries; for examples, it was $12.1 \%$ in Turkey (Sari et al., 2009). Furthermore, our results show the prevalence of HUA was higher than the previous study in 2006 as $10.6 \%$ (Lohsoonthorn et al., 2006). When we compared with the study in rural areas, our results were also higher than the previous study in Khon kaen province, Thailand (Premgamone et al., 2011), and mainland China (Liu et al., 2015). Our reports also showed that the prevalence of HUA was high in men, which was higher than in both developed and developing countries.

In this present study, we used an rs2280205 and rs6820230 polymorphisms of SLC2A9 gene to evaluate the effects of genetic predispositions to HUA risk, this is the first genetic study among Thais in the urban area. Since the previous studies have been demonstrated as possibly interfering with excretion of urate, and also changing the activity of GLUT9 that can facilitate its reabsorption and leading to HUA; or with other variants, and then interfere in uric acid excretion (Sun et al., 2012; Hurba et al., 2014; Merriman, 2015). Moreover, the function of GLUT9 is a high-capacity uric acid transporter that is expressed in the kidney, liver, and several other tissues (Wright et al., 2010). Our study figures that the rs2280205 (G/A), rs6820230 (C/T) variants and the SLC2A9 gene haplotype did not influence on HUA risk in Thais. The lack of association might be due to the minor alleles and homozygous genotypes distributions of rs2280205 and rs6820230 were similar between cases and controls (Table 2), which we reported a large proportion of the minor alleles and their homozygous genotypes for the rs2280205 and rs6820230. The previous study in Czech populations and 
Cameroonians also did not find an association with HUA and gout (Hurba et al., 2014; Nkeck et al., 2018), which found the same distribution of minor alleles (G) and their homozygous genotypes (G/A) given the same ethnic origin of both cases and control subjects. In contrast with our present study and some previous studies (McArdle et al., 2008; Chisnall, 2014; Hurba et al., 2014; Nkeck et al., 2018) indicated that rs2280205 variant was reduced the risk of gout (32\%) but rs6820230 variant was associated with susceptibility to gout in Caucasian, adjusted odds ratio 1.20 to 1.90. Furthermore, the several genome-wide association studies (GWAS) have demonstrated an association of SLC2A9 gene with SUA (Wright et al., 2010; Liu et al., 2011) and the risk of gout (Dehghan et al., 2008; Kottgen et al., 2013; Dalbeth et al., 2016). Although previous studies have investigated other SLC2A9 gene in various ethnic populations, our study is the first to investigate the presence and effects of rs2280205 and rs6820230 variants among the Thai population in the urban area. Our study had some limitations, this study is an urban community based cross-sectional analytical study, that to describe the prevalence of HUA and its potential association between the only two variants of SLC2A9 gene and risk of HUA among Thai population in a small urban area. Therefore, further studies with relatively large samples are required with an emphasis on other single nucleotide polymorphisms of SLC2A9 gene such as rs3733591, rs12510549, rs16890979, and rs1014290 variants (Zhang et al., 2016; Lee et al., 2017), and Other genetic variants such as WD40 repeat protein 1 (WDR1) (Lui et al., 2016), NACHT, LRR and PYD domains-containing protein 3 (NALP3) (Wang et al., 2015), SLC17A, SLC16A9, SLC22A11, GCKR, and INHBC etc. (Reginato et al., 2012), including to investigate gene-gene interactions and gene-environmental interactions among the Thai population in both urban and rural area. Furthermore, the role of environmental factors, such as red meat (Roddy and Choi, 2014), sugar-sweetened beverages (Choi and Curhan, 2008), alcohol consumption (Bhole et al, 2010), obesity (Cea Soriano et al, 2011), hypertension (Bhole et al, 2010; Rothenbacher et al, 2011), and dyslipidemia (Peng et al, 2015; Ali et al, 2019) etc., is equally important because it determines the individual risk of gout and HUA. The mutations on the urate transport could manifest later in life or in the context of a hyperuricemic diet (Major et al., 2018). Therefore, the follow up of people who affected by rs2280205 and rs6820230 variants in a cohort study will provide better evidence concerning their implication.

In conclusion, our study is the first urban community based cross-sectional analytical study of the prevalence of HUA and association of the rs2280205 and rs6820230 variants in the SLC2A9 gene with the development of HUA in Thais living in an urban area. The prevalence of HUA was high and combined with information from previous studies, we conclude that these variants are not associated with HUA.

\section{ACKNOWLEDGMENTS}

We thank Dr.Kitsarawut Khuancharee for statistical advice and for comments on an earlier draft of the manuscript. We also thank the Department of Biochemistry, Faculty of Medicine Srinakharinwirot University for their kind help and support. We also express our cordial thanks to the staff of the laboratory of the HRH Princess Maha 
Chakri Sirindhorn Medical Center (MSMC) for blood biochemical analysis. This research was financially supported by the MSMC (grant number 275/2561).

\title{
CONFLICTS OF INTEREST
}

\author{
The authors declare no conflict of interest.
}

\section{REFERENCES}

Ali N, Perveen R, Rahman S, Mahmood S, et al. (2018). Prevalence of hyperuricemia and the relationship between serum uric acid and obesity: A study on Bangladeshi adults. PLoS One. 13: e0206850.

Ali N, Rahman R, Islam S, Haque T, et al. (2019). The relationship between serum uric acid and lipid profile in Bangladeshi adults. BMC cardiovasc disord. 19: 42.

Bardin T, Bouee S, Clerson P, Chales, et al. (2016). Prevalence of Gout in the Adult Population of France. Arthritis Care Res. 68: 261-266.

Bhole V, Vera M, Rahman M, Krishnan E and Choi H (2010). Epidemiology of gout in women: Fifty-two-year followup of a prospective cohort. Arthritis Rheum. 62: 1069-1076.

Cea Soriano L, Rothenbacher D, Choi HK and Garcia LA (2011). Contemporary epidemiology of gout in the UK general population. Arthritis Res Ther. 13: R39.

Chisnall A (2014). The role of SLC2A9 Variants in Hyperuricemia and Gout. Master's Thesis, Faculty of science, University of Otago.

Choi HK and Curhan G (2008). Soft drinks, fructose consumption, and the risk of gout in men: prospective cohort study. BMJ. 336: 309-312.

Dalbeth N, Merriman TR and Stamp LK (2016). Gout. Lancet. 388: 2039-2052.

Dehghan A, Kottgen A, Yang Q, Hwang SJ, et al. (2008). Association of three genetic loci with uric acid concentration and risk of gout: a genome-wide association study. Lancet. 372: 1953-1961.

Hurba O, Mancikova A, Krylov V, Pavlikova M, et al. (2014). Complex analysis of urate transporters SLC2A9, SLC22A12 and functional characterization of non-synonymous allelic variants of GLUT9 in the Czech population: no evidence of effect on hyperuricemia and gout. PloS one. 9: e107902.

Kottgen A, Albrecht E, Teumer A, Vitart V, et al. (2013). Genome-wide association analyses identify 18 new loci associated with serum urate concentrations. Nat. Genet. 45: 145-54.

Lee YH, Seo YH, Kim JH, Choi SJ, et al. (2017). Associations between SLC2A9 polymorphisms and gout susceptibility : A meta-analysis. Z. Rheumatol. 76: 64-70.

Liu R, Han C, Wu D, Xia X, et al. (2015). Prevalence of Hyperuricemia and Gout in Mainland China from 2000 to 2014: A Systematic Review and Meta-Analysis. Biomed. Res. Int. 2015: 762820.

Liu WC, Hung CC, Chen SC, Lin MY, et al. (2011). The rs1014290 polymorphism of the SLC2A9 gene is associated with type 2 diabetes mellitus in Han Chinese. Exp. Diabetes Res. 2011: 527520.

Liu LJ, Zhang XY, He N, Liu K, et al. (2016). Genetic variation in WDR1 is associated with gout risk and gout-related metabolic indices in the Han Chinese population. Genet. Mol. Res. 15: gmr7381.

Lohsoonthorn V, Dhanamun B and Williams MA (2006). Prevalence of hyperuricemia and its relationship with metabolic syndrome in Thai adults receiving annual health exams. Arch. Med. Res. 37: 883-889.

Major TJ, Topless RK, Dalbeth N and Merriman TR (2018). Evaluation of the diet wide contribution to serum urate levels: meta-analysis of population based cohorts. BMJ. 363: k3951.

Merriman TR (2015). An update on the genetic architecture of hyperuricemia and gout. Arthritis Res Ther. 17: 98.

Nagahama K, Iseki K, Inoue T, Touma T, et al. (2004). Hyperuricemia and cardiovascular risk factor clustering in a screened cohort in Okinawa, Japan. Hypertens. Res. 27: 227-233.

Nakanishi N, Yoshida H, Nakamura K, Suzuki K, et al. (2001). Predictors for development of hyperuricemia: an 8-year longitudinal study in middle-aged Japanese men. Metabolism. 50: 621-626.

Nkeck JR, Singwé Ngandeu M, Ama Moor V, Nkeck JP, et al. (2018). Genetic analysis for rs2280205 (A>G) and rs2276961 (T>C) in SLC2A9 polymorphism for the susceptibility of gout in Cameroonians: a pilot study. BMC Res Notes. 11: 230.

Peng TC, Wang CC, Kao TW, James YH, et al. (2015). Relationship between hyperuricemia and lipid profiles in US adults. Biomed. Res. Int. 2015: 127596.

Premgamone A, Ditsatapornjaroen T, Jindawong B, Krusun N, et al. (2011). The Prevalence of Hyperuricemia and Associated Factors in the Rural Community, Khon Kaen Province. Srinagarin. Med. J. 26: 41-47.

Reginato AM, Mount DB, Yang I and Choi HK (2012). The genetics of hyperuricaemia and gout. Nat. Rev. Rheumatol. 8: 610-621.

Roddy E and Choi H (2014). Epidemiology of Gout. Rheum. Dis. Clin. North Am. 40: 155-175.

Genetics and Molecular Research 19 (1): gmr18511

CFUNPEC-RP www.funpecrp.com.br 
Rothenbacher D, Primatesta P, Ferreira A, Cea-Soriano L, et al. (2011). Frequency and risk factors of gout flares in a large population-based cohort of incident gout. Rheumatology. 50: 973-981.

Sari I, Akar S, Pakoz B, Sisman AR, et al. (2009). Hyperuricemia and its related factors in an urban population, Izmir, Turkey. Rheumatol. Int. 29: 869-874.

Sole X, Guino E, Valls J, Iniesta R, et al. (2006). SNPStats: a web tool for the analysis of association studies. Bioinformatics. 22: 1928-1929.

Sun L, Zeng X, Yan C, Sun X, et al. (2012). Crystal structure of a bacterial homologue of glucose transporters GLUT14. Nature. 490: 361-366.

Terkeltaub RA (2003). Clinical practice. Gout. N. Engl. J. Med. 349: 1647-1655.

Wang LF, Ding YJ, Zhao Q and Zhang XL (2015). Investigation on the association between NLRP3 gene polymorphisms and susceptibility to primary gout. Genet. Mol. Res. 14: 16410-16414.

WHO (2004). Appropriate body-mass index for Asian populations and its implications for policy and intervention strategies. Lancet. 363: 157-163.

Wright AF, Rudan I, Hastie ND and Campbell H (2010). A complexity of urate transporters. Kidney Int. 78: 446-452.

Zhang X, Yang X, Wang M, Li X, et al. (2016). Association between SLC2A9 (GLUT9) gene polymorphisms and gout susceptibility: an updated meta-analysis. Rheumatol. Int. 36: 1157-1165.

Zhu Y, Pandya BJ and Choi HK (2011). Prevalence of gout and hyperuricemia in the US general population: the National Health and Nutrition Examination Survey 2007-2008. Arthritis Rheum. 63: 3136-3141.8 